\title{
A questão da co-responsabilidade prevista na Estratégia Saúde da Família
}

\author{
Carmen Rosario Ortiz Gutierrez Gelinski*
}

\section{Resumo}

O novo modelo assistencial em saúde proposto em 1997 e plasmado na Estratégia Saúde da Família (ESF) tem por foco a atenção básica à saúde e as ações de promoção e prevenção. Configura um novo modo de agir em saúde em que as responsabilidades pelos cuidados devem ser compartilhadas pelas famílias e pelas equipes de Saúde Familiar (SF). Este artigo visa resgatar em documentos oficiais o sentido outorgado ao termo co-responsabilidade e explorar a compreensão que as famílias têm sobre o tema, a partir de relatos de pesquisa de campo junto a famílias atendidas pela ESF. O artigo aponta que enquanto os operadores em saúde, notadamente as equipes de SF, têm uma lista de atribuições que delimitam a sua atuação, as famílias não sabem como executar a sua parte da co-responsabilidade.

Palavras-chave: co-responsabilidade, Estratégia Saúde da Família, Atenção Básica.

\section{Introdução}
Estratégia Saúde da Família (ESF), enquanto estratégia orga- Anizativa da Atenção Primária ou Básica à Saúde no SUS, foca suas ações na promoção da saúde e prevenção de doenças. Confi- gura um novo modo de agir em saúde em que as responsabilidades pelos cuidados passam a ser compartilhadas pelas famílias e pelas equipes de saúde da família.

\footnotetext{
Professora do Departamento de Economia e Relações Internacionais da Universidade Federal de Santa Catarina, Florianópolis. Endereço eletrônico: carmeng@cse.ufsc.br. indistintamente, no contexto histórico brasileiro a acepção mais usada é "Atenção Básica à Saúde”.
}
1 Conforme será esclarecido mais adiante, embora os termos com frequência sejam usados 
Responsabilidade, co-responsabilidade, autonomia, co-gestão são termos que aparecem com frequiência nos documentos oficiais que tratam da saúde da família. Percebe-se que as menções são feitas em dois sentidos: como delimitação das competências de cada unidade da federação (governo central, estados ou municípios) e como estabelecimento das responsabilidades entre os agentes envolvidos, notadamente os usuários e os trabalhadores em saúde. Observa-se que no primeiro sentido há uma clara definição das funções que cada nível da federação deve desempenhar. Já no segundo sentido há uma situação polar: enquanto os trabalhadores em saúde (médicos, enfermeiros, agentes comunitários de saúde, etc.) têm as suas funções estabelecidas, parece não haver o mesmo nível de clareza no que tange aos encargos das famílias nas co-responsabilidades pelos cuidados em saúde. Diante disso, alguns questionamentos são pertinentes: Será que as famílias sabem mesmo o que é serem co-responsáveis pelos cuidados? Será que elas estão cientes dos direitos e das obrigações que elas têm no novo formato da atenção básica? Os profissionais de saúde repassam essas informações aos usuários? E mais, será que elas possuem os recursos (sociais, emocionais e técnicos) para dar conta da sua parte na co-responsabilidade?

No dicionário Aurélio o termo responsabilidade se refere a: 1) Qualidade ou condição de responsável. 2) Condição de causador de algo; culpa. 3) Aquilo (tarefa, ação) pelo qual alguém é responsável; obrigação, dever. 4) Condição jurídica de quem, sendo considerado capaz de conhecer e entender as regras e leis e de determinar a própria vontade e ações, pode ser julgado e punido por algum ato que cometeu (FERREIRA, 2008). A última dessas definições fornece os elementos a partir dos quais pretendemos discutir neste texto a questão da co-responsabilidade prevista na Estratégia Saúde da Família: a noção de que alguém só pode ser julgado com base no conhecimento ou entendimento que tenha das regras ou leis às quais se encontra submetido.

Sem pretender esgotar o assunto, a intenção deste artigo é explorar a idéia de que as famílias não estão cientes das respon- 
sabilidades que o novo modelo de atenção em saúde lhes atribui, possivelmente por não conhecerem o programa que sintetiza essas diretrizes (no caso a ESF) ou talvez por não saberem da sua ênfase preventiva e de promoção à saúde.

De modo mais específico, este artigo visa resgatar em documentos oficiais o sentido outorgado ao termo co-responsabilidade e as atribuições tanto das equipes de saúde quanto das famílias no exercício dessa co-responsabilidade. Além disso, analisa parte dos dados de uma pesquisa de campo realizada em 2010, junto às famílias atendidas por equipes de ESF em um bairro do município de Florianópolis. a qual permitiu explorar com maior profundidade a compreensão que aquelas famílias têm das suas responsabilidades ${ }^{2}$.

\section{Mudança de modelo assistencial e a questão da co- responsabilidade na ESF}

A Conferência Internacional sobre Cuidados Primários de Saúde, realizada em Alma Ata em 1978, é considerada o marco que define a atenção primária ${ }^{3}$ como novo modelo de assistência aos cuidados em saúde e teve uma influência decisiva na política de saúde brasileira. $\mathrm{O}$ anterior modelo ficou conhecido como "medicocêntrico" ou "hospitalocêntrico" pela sua ênfase no médico, na doença, nos hospitais e nos aspectos curativos, em detrimento dos

2 Foram entrevistadas no ano de 2010, 14 famílias em duas comunidades atendidas pela ESF. Os dados foram submetidos à análise temática do discurso. Para mais detalhes, ver Gelinski (2010).

3 De acordo com a Conferência, os cuidados primários de saúde são definidos como: "Cuidados essenciais de saúde baseados em métodos e tecnologias práticas, cientificamente bem fundamentadas e socialmente aceitáveis, colocadas ao alcance universal de indivíduos e famílias da comunidade, mediante sua plena participação e a um custo que a comunidade e o país possam manter em cada fase de seu desenvolvimento, no espírito de autoconfiança e automedicação. (...) Representam o primeiro nível de contato dos indivíduos, da família e da comunidade com o sistema nacional de saúde, pelo qual os cuidados de saúde são levados o mais proximamente possível aos lugares onde pessoas vivem e trabalham, e constituem o primeiro elemento de um continuado processo de assistência à saúde" (DECLARAÇÃO,1978). 
aspectos preventivos e de promoção à saúde ${ }^{4}$. No relacionamento com os pacientes, a medicina convencional concebia os usuários como receptores passivos das prescrições médicas. Nesse sentido, a novidade na atenção básica seria a concepção dos indivíduos e famílias como co-responsáveis pelas ações em saúde.

Cabe destacar que no contexto histórico brasileiro a acepção usada para se referir à atenção primária é "atenção básica à saúde”. Sobre isso, Fausto e Matta (2007) assinalam que a despeito dos termos serem usados indistintamente, o mais frequiente tem sido empregar a expressão "primária" para se referir às experiências internacionais e "básica" para a experiência brasileira. O termo "atenção básica" teria sido introduzido no Brasil em 1996 pela NOB-SUS 01/96 "a opção pelo termo deveu-se essencialmente a que nesse momento, existia, do ponto de vista ideológico uma forte resistência de alguns atores ao termo atenção primária à saúde principalmente porque (...) o propósito seletivo prevalecia na concepção veiculada por organismos internacionais" (FAUSTO e MATTA, 2007, p.61)

Num cenário em que ganhariam prevalência os modelos internacionais de atenção primária, o Programa Saúde da Família (PSF) surgiria no Brasil em 1994 como a estratégia organizativa da atenção básica à saúde no Sistema Único de Saúde (SUS). Andrade Barreto e Bezerra (2006, p.807) alertam que "a gestação do PSF não pode ser grosseiramente resumida a uma súbita replicação de modelos internacionais da medicina da família ou atenção à saúde simplificada". O PSF é resultado do amadurecimento de um conjunto de experiências de implantação da atenção primária no país, desenvolvidas desde a década de 1940. Corbo, Morosini e Pontes (2007) destacam que o PSF seria o quinto ciclo de expan-

\footnotetext{
4 Franco e Merhy (1999) se referem a esse modelo como "biomédico" ou de "medicina científica", pois desenvolve-se "a partir de recursos que são disponibilizados à assistência à saúde, centrados no conhecimento especializado, equipamentos/máquinas e fármacos" (p.12). Os autores consideram que esse modelo assistencial era "procedimento centrado" e não "usuário centrado", haja vista que "(...) o principal compromisso do ato de assistir à saúde é com a produção de procedimentos. Apenas secundariamente existe compromisso com as necessidades dos usuários”. (p.13).
} 
são da atenção primária à saúde no país. Antes dele ocorreram experiências mais restritas ou de cunho local/regional, tais como a proposta da Medicina Geral e Comunitária, com início em Porto Alegre em 1983; a Ação Programática em Saúde, em São Paulo nos anos 1970; o Modelo Médico de Família, em Niterói em 1992; e o modelo de Defesa da Vida, criado em Campinas no fim dos anos 1980. Dentre as experiências já existentes no país, esses autores destacam o Programa de Medicina da Família de Niterói e o Serviço de Saúde Comunitária de Grupo Hospitalar Conceição de Porto Alegre como aquelas que teriam repercussão mais imediata na formulação primeiramente do Programa de Agentes Comunitários de Saúde (PACS) em 1991, cuja cobertura inicial se restringia ao Nordeste. Esse programa assentaria as bases para o tratamento da saúde a partir de base territorial de incumbência de cada agente. Em 1994 o Ministério da Saúde amplia esse programa com a implantação do Programa de Saúde da Família (PSF) e em 1997 altera a concepção do programa que passa a ser denominado Estratégia Saúde da Família ${ }^{5}$.

A partir dos documentos que norteiam a ESF (BRASIL, 1997; BRASIL, 2010) é possível entender a configuração que a saúde da família tem e os sentidos que o termo "responsabilidade" assume neles. Desde já se exclui desta discussão a questão da responsabilidade institucional de cada esfera governamental (Ministérios, Secretarias, Estados, municípios, etc.). A discussão deve estar focada na compreensão da co-responsabilidade entre os envolvidos no cotidiano da saúde da família e nas implicações que esse conceito pode ter na delegação de responsabilidades para os usuários.

5 Ribeiro (2004) chama a atenção para o fato de que a adoção dos termos programa ou estratégia está cheio de questionamentos e argumentos a favor do uso de cada um deles. O documento oficial que estabelece a reorientação (BRASIL, 1997, p.8) destaca que é mais adequado considerá-lo uma estratégia ao invés de programa, pois “(...) foge à concepção usual dos demais programas concebidos no Ministério da Saúde, já que não é uma intervenção vertical e paralela às atividades dos serviços de saúde. Pelo contrário, caracteriza-se como uma estratégia que possibilita a integração e promove a organização das atividades em um território definido, com o propósito de propiciar o enfrentamento e resolução dos problemas identificados". 
Conforme consta no site do Ministério da Saúde (BRASIL, 2010), a nova visão do trabalho proposta pela atenção básica e plasmada na ESF busca superar a atuação em saúde centrada unicamente na doença. Dentro dos princípios fundamentais da atenção básica (integralidade, qualidade, equiidade e participação social) "as equipes Saúde da Família estabelecem vínculo com a população, possibilitando o compromisso e a co-responsabilidade destes profissionais com os usuários e a comunidade" (p.1). O ponto central da ESF estaria no "(...) estabelecimento de vínculos e a criação de laços de compromisso e de co-responsabilidade entre os profissionais de saúde e a população. (BRASIL, 1997, p.7).

No arcabouço conceitual da Estratégia Saúde da Família é possível destacar alguns elementos que possibilitam qualificar a responsabilidade das equipes para com as famílias. O primeiro elemento de definição da responsabilidade das equipes é dado pelo território, isto é pela delimitação (adscrição) da população a ser atendida: "Cada equipe se responsabiliza pelo acompanhamento de cerca de 3 a 4 mil e 500 pessoas ou de mil famílias de uma determinada área, e estas passam a ter co-responsabilidade no cuidado à saúde." (p.1). Junto a essa população as equipes teriam por tarefa "(...) intervir sobre os fatores de risco aos quais a comunidade está exposta; (...) prestar assistência integral, permanente e de qualidade; (...) realizar atividades de educação e promoção da saúde”. (BRASIL, 2010, p.1).

O segundo elemento se refere à atribuição de tarefas das equipes. No documento de 1997, onde constam as linhas mestras da reorientação do modelo assistencial (BRASIL, 1997), estão listadas as funções de cada um dos membros (médico, enfermeiro, auxiliar de enfermagem e agente comunitário de saúde - ACS). O mesmo documento define que as equipes devem realizar visitas domiciliares, internação domiciliar e participar de grupos comunitários. Essas atribuições estão definidas em torno da população pela qual cada equipe é responsável.

O terceiro elemento de definição de responsabilidade se refere à estreita relação entre responsabilidade e vínculo. Consta no 
documento de reorientação do novo modelo assistencial (BRASIL, 1997, p.34) que o seu potencial transformador estaria nos vínculos de compromisso e co-responsabilidade que se estabelecem entre os serviços de saúde e a população. Ao invés da unidade de saúde "ficar esperando" pela população, incumbe os ACS de visitar as famílias nos seus lares, de modo a aproximar os serviços de saúde das famílias. Na atuação da equipe, o ACS desempenha papel fundamental, pois será ele o principal responsável pelo estabelecimento do vínculo com as famílias.

\section{A parte da co-responsabilidade das famílias}

A despeito das equipes terem as suas atribuições bem definidas não há menção nos documentos da ESF ao exercício da co-responsabilidade das famílias. A exceção está num documento relativamente recente, intitulado Carta dos direitos dos usuários da saúde (BRASIL, 2007), texto elaborado de modo conjunto pelo Ministério da Saúde, pelo Conselho Nacional de Saúde e pela Comissão Intergestora Tripartite. A Carta contém os princípios que devem assegurar o direito aos sistemas de saúde, quer sejam públicos ou privados. Dentre os seis direitos que a carta elenca, o quinto "assegura as responsabilidades que o cidadão também deve ter para que seu tratamento aconteça de forma adequada"”. Para isso ele deve se comprometer a (op. cit., p. 6-7):

6 Os seis princípios rezam (BRASIL, 2007): "O primeiro assegura ao cidadão o acesso ordenado e organizado aos sistemas de saúde, visando a um atendimento mais justo e eficaz. (...) O segundo assegura ao cidadão o tratamento adequado e efetivo para seu problema, visando à melhoria da qualidade dos serviços prestados. (...) O terceiro assegura ao cidadão o atendimento acolhedor e livre de discriminação, visando à igualdade de tratamento e a uma relação mais pessoal e saudável. (...) O quarto assegura ao cidadão o atendimento que respeite os valores e direitos do paciente, visando a preservar sua cidadania durante o tratamento. (...) $\mathrm{O}$ quinto assegura as responsabilidades que $\mathrm{o}$ cidadão também deve ter para que seu tratamento aconteça de forma adequada. (...) O sexto assegura o comprometimento dos gestores para que os princípios anteriores sejam cumpridos." 
I. Prestar informações apropriadas nos atendimentos, nas consultas e nas internações sobre queixas, enfermidades e hospitalizações anteriores, história de uso de medicamentos e/ou drogas, reações alérgicas e demais indicadores de sua situação de saúde.

II. Manifestar a compreensão sobre as informações e/ou orientações recebidas e, caso subsistam dúvidas, solicitar esclarecimentos sobre elas.

III. Seguir o plano de tratamento recomendado pelo profissional e pela equipe de saúde responsável pelo seu cuidado, se compreendido e aceito, participando ativamente do projeto terapêutico.

IV. Informar ao profissional de saúde e/ou à equipe responsável sobre qualquer mudança inesperada de sua condição de saúde.

V. Assumir responsabilidades pela recusa a procedimentos ou tratamentos recomendados e pela inobservância das orientações fornecidas pela equipe de saúde.

VI. Contribuir para o bem-estar de todos que circulam no ambiente de saúde, evitando principalmente ruídos, uso de fumo, derivados do tabaco e bebidas alcoólicas, colaborando com a limpeza do ambiente.

VII. Adotar comportamento respeitoso e cordial com os demais usuários e trabalhadores da saúde.

VIII. Ter sempre disponíveis para apresentação seus documentos e resultados de exames que permanecem em seu poder.

IX. Observar e cumprir o estatuto, o regimento geral ou outros regulamentos do espaço de saúde, desde que estejam em consonância com esta carta.

X. Atentar para situações da sua vida cotidiana em que sua saúde esteja em risco e as possibilidades de redução da vulnerabilidade ao adoecimento. 
XI. Comunicar aos serviços de saúde ou à vigilância sanitária irregularidades relacionadas ao uso e à oferta de produtos e serviços que afetem a saúde em ambientes públicos e privados.

A respeito do documento, alguns destaques merecem ser feitos. Enquanto elemento normativo ele ainda carece de maior divulgação entre usuários da saúde. A mera existência de um documento não garante o conhecimento do mesmo por parte dos que deveriam utilizá-lo. $\mathrm{O}$ documento, pelo seu caráter por vezes irrealista e pela sua redação apurada, própria de um ambiente jurídico, pode ser pouco acessível para a população alvo. Quanto à noção de seguir o tratamento recomendado pelo profissional e pela equipe, vale destacar que a ênfase dada recai em seguir o tratamento e em nenhum momento se fala em compreender o itinerário terapêutico dos usuários. A ênfase está na questão de como o usuário tem que se comportar em relação aos serviços oferecidos, mas falta apontar como os serviços devem se comportar em relação aos usuários, mais especificamente no que se refere aos aspectos relativos ao itinerário dos usuários: a quem eles recorrem em casos de doenças, quais as estratégias que as famílias montam no cotidiano para lidar com situações de doença e descobrir as dificuldades que elas têm. Quanto à afirmação de que os usuários devem informar sobre qualquer mudança inesperada na sua condição de saúde, haveria que se verificar se na prática cotidiana das unidades de saúde (com horários e dias pré-definidos para cada micro área) e com a realidade do pouco tempo das famílias se estas teriam condições de relatarem mudanças inesperadas de saúde. $\mathrm{O}$ documento ignora que há problemas que afetam a saúde e que extrapolam comportamentos individuais ou até mesmo coletivos dos usuários. A menção é feita a respeito da indefinição sobre a quem os usuários devem recorrer para resolver problemas que tenham relação com a saúde. Por exemplo, como o usuário pode cuidar de aspectos sanitários do seu entorno se tem esgoto a céu aberto correndo nas proximidades da sua casa? Ou ainda, como conseguir recursos para resolver certos pro- 
blemas de infra-estrutura mesmo que em esquema de mutirão? ${ }^{7}$ Há indefinição do ponto de vista dos usuários a respeito de quem pode resolver problemas, de quem pode ser responsabilizado quando há problemas de infra-estrutura que afetam a saúde. Se o documento se refere a atentar para situações da vida cotidiana em que a saúde esteja em risco e as possibilidades de redução da vulnerabilidade ao adoecimento, é impossível ignorar que a saúde está envolvida com vários setores da vida social que não só o atendimento médico. A saúde dos moradores de uma comunidade precária implica a articulação de um conjunto de outros serviços e não apenas dos oferecidos pelas unidades de saúde. O que, de fato, se constata é que não existe uma articulação institucional para resolver esses problemas estruturais. Uma coisa é saber que a população tem direito a uma vida digna, outra é saber o que o Estado tem feito de concreto e de forma articulada para atingir isso.

Há uma distância significativa entre as responsabilidades preconizadas pela Carta dos Direitos dos Usuários e o que de fato as famílias entendem que precisam saber para melhor aproveitar os serviços que the são oferecidos e atuar de modo sinérgico com as equipes de saúde da família.

A pesquisa de campo realizada junto às famílias atendidas pela ESF em um bairro da cidade de Florianópolis permitiu deduzir alguns aspectos práticos que poderiam definir as responsabilidades das famílias:

- seguir orientações quanto à medicação;

\footnotetext{
7 Grisotti e Patrício (2006) relatam a dificuldade de uma comunidade de Florianópolis na tentativa de obter um pequeno financiamento junto ao Conselho Municipal de Saúde (CMS) para projeto de educação ambiental que buscava resolver problemas de lixo da comunidade. Os moradores solicitaram recursos apenas para a compra de material, já que estariam dispostos a construírem as lixeiras, em regime de mutirão. Como o CMS arguiiu que havia limites burocráticos para viabilizar ajuda financeira foi sinalizada a possibilidade de celebrar convênio junto à Secretaria da Saúde (SMS) para aprovação do projeto. Foi marcada reunião com o secretário da SMS, com membros da Comissão de Meio Ambiente e com representantes do CMS. No entanto até o fim daquela pesquisa (quatro meses depois) ainda não havia relato de resolutividade para a necessidade apontada.
} 
- saber os dias de marcação de consulta;

- distinguir entre episódios que se configurem como emergência daqueles a serem tratados em consultas agendadas

- seguir orientações preventivas;

- insistir para marcar consulta com especialista ou exame de alta complexidade.

Sobre este último ponto cabe destacar que se trata de um dos aspectos de maior insatisfação entre os usuários e que melhor retrata a idéia de que o chamado à co-responsabilidade na realidade pode estar se tratando de um repasse de responsabilidades para as famílias. Em mais de uma ocasião em que os ACS estavam presentes na entrevista e os pacientes reclamavam da demora, insistiam que os usuários deveriam continuar tentando e insistindo. Parece como se o repasse da responsabilidade pela marcação fosse de exclusiva competência do usuário.

ACS: (...) Os que não conseguiram têm que continuar tentando marcar. Eles (a prefeitura) alegam isso: "não tem vaga". A gente até tenta. Eu falo com o moço da marcação e ele diz "não tem vaga". A gente comenta isso na reunião do grupo, mas é isso, tem que aguardar.

USUÁRIA: mas não adianta ... eles não vão ...

ACS Mas é uma coisa que você tem que insistir. Podem lhe chamar de chata, não faz mal, volte lá, fique perguntando para o atendente "meus exames já foram marcados?". Continue insistindo.

USUÁRIA: o médico do HU disse assim "a Sra vai ter que se internar. Vai ficar internada, mas tem que ter o 'urgente' (no documento) para fazer isso aî”. Só que eu já fiquei boa, não preciso internar e não foi marcado.

ACS: Nós vamos continuar insistindo... o que não pode é ficar sossegado em casa. Fique lá insistindo. É o que tem que fazer. Vai perguntando, marca de volta a consulta e diz "o exame não foi marcado" e fica indo lá. É um direito seu.

marcado" e fica indo lá. E um direito seu. 
Os relatos tendem a mostrar que, num determinado momento, o insucesso na marcação da consulta seria decorrente da falta de insistência do paciente. O desânimo toma conta dos pacientes entrevistados que aparentam não querer insistir mais, mesmo que essa atitude possa ser interpretada como "ficar sossegado em casa". Cabe ressaltar que para o usuário "ficar insistindo" significa dispor de tempo para tentar diversas vezes, até conseguir a tão almejada consulta. Na prática, as constantes negativas em muitos casos levam os usuários a desistir para evitar atritos e dissabores. Enquanto ligação do usuário com a política pública, o agente de saúde tenta conseguir a consulta ou exame solicitado, mas diante da impossibilidade repassa para o usuário o poder de pressão ou o dever de lutar por um direito seu.

Nas discussões propostas sobre as demandas que as famílias fazem às unidades de saúde, percebemos que as noções do que é a atenção básica, secundária e terciária não estão claras para as entrevistadas. Por desconhecer os limites de cada nível de atenção, os pacientes passam a exigir algo que não está previsto pelo nível de atenção que a unidade de saúde oferece. $O$ conhecimento que os usuários têm se limita a horários para marcação de consultas ou critérios que definem o que seria objeto de uma consulta ou de um atendimento de emergência. Quando questionadas diretamente sobre se conheciam a ESF, as entrevistadas foram unânimes ao responder que não. Essa negação revela não apenas a falta de conhecimento sobre questões burocráticas relativas ao atendimento nas Unidades Locais de Saúde (ULS), mas fundamentalmente o desconhecimento do modelo de saúde que o SUS lhes coloca a disposição - ancorado em ações preventivas e de promoção da saúde. Tal vez por isso algumas entrevistadas desmereçam as visitas dos ACS, pela ênfase que essas visitas têm no repasse de noções gerais de cuidados, e não de tratamento efetivo de doenças graves ou lesões que estariam fora do foco de atuação da atenção básica.

Algumas entrevistadas afirmaram "ter ouvido falar" da Estratégia Saúde da Família, mas quando era solicitado que falassem o que sabiam, confessavam não saber do que se tratava. Em uma 
das entrevistas ao ser feita a questão sobre o conhecimento da ESF, a ACS que se encontrava presente puxou um folheto e disse "vou aproveitar para deixar para a senhora um folheto que peguei na universidade sobre o programa. Fala exatamente sobre o que é o agente comunitário e sobre o programa".

Esse aspecto serviu de alerta para refletir sobre o real sentido da co-responsabilidade prevista pela ESF: foi se delineando a quase impossibilidade de tornar a população co-responsável de um programa que eles desconhecem. Nas entrevistas percebe-se o quanto gritante é o desequilíbrio de saberes sobre o funcionamento do programa e do que pode e não pode ser cobrado dele. Chega a se questionar se os usuários sabem que as unidades de saúde são apenas a porta de entrada para o sistema; mesmo aqueles usuários que dispõem de informações as têm de modo incompleto. As respostas se reduzem às tentativas de explicar a estratégia e o papel que desempenham nela os ACS. Uma entrevistada se referiu à ACS que atende a comunidade como a "líder do bairro", enquanto outra a denominou de "responsável pela rua".

Eles vêm uma vez por mês aqui. Todo morro tem um líder, né? Aí tem uma pessoa do posto que faz o cadastro das pessoas para saber como está, como não está. Ela que faz os documentos se precisar fazer algum exame, alguma coisa ela traz, ela que dá o recado. Os ACS são os olhos da comunidade perante o posto. (Usuária 10)

[Sabe o que é a ESF?JJá ouvi falar, mas não sei o que significa. (Usuária 5)

[Sabe o que é a ESF?] Mais ou menos lo que a Sra. Sabe?] não sei nada. (Usuária 2)

Outra entrevistada confunde a ESF com a reunião que tem uma vez por mês do bolsa-escola.

Às vezes tem uma reunião lá. Essa cesta básica tem uma reunião uma vez por mês. Nessa reunião eles perguntam sobre saúde, sobre a casa. Essa cesta básica que ganham. Eles querem saber se os filhos estão comendo, se gostam ou não gostam (da comida). Nessa cesta vem tudo de quilo: um quilo de arroz, um de feijão, um de açúcar, um óleo, uma caixinha de ovos, vem carne de galinha. E depois vêm as verduras: 
laranja, batata. Isso pega no supermercado. Faz tudo a papelada primeiro direitinho, vai um carimbo, entrega para eles e tem que ter a assinatura do posto e da médica. Passam receita para os alimentos. (...) As "gurias" que fazem a reunião (da cesta) perguntam se está tudo bem, falaram se tiver alguma reclamação tem que ser agora, depois não adianta reclamar. (Usuária 3)

Outra entrevistada na frente da ACS, responde de modo dúbio, talvez como forma de mascarar o seu desconhecimento. "Já ouvi falar, mas nunca ouvi nada". (Usuária 4)

Uma outra entrevistada - que durante a entrevista havia reclamado da falta de visitas das ACS - afirmou:

Ouvi falar, mas não saberia dizer o que é. Se elas viessem por aqui, as pessoas saberiam o que é. Aqui a população cresceu muito, mudou muito a rotina dos postos de saúde. A equipe que trabalhava bem saiu. (Usuária 11)

A entrevistada faz menção a uma equipe que trabalhava na região dois anos antes. Considera que essa equipe era mais efetiva e que em particular a ACS que cuidava dessa micro área se preocupava em dar palestras ou em trazer pessoas da universidade para fazê-lo. Essa afirmação revela o quanto a divulgação da informação sobre a estrutura e o funcionamento do programa está atrelada ao vínculo que se cria entre a população e os ACS e ao agir dos indivíduos inseridos no programa. É como se em certa forma a divulgação dependesse da "boa vontade" dos funcionários do posto e não estivesse ligada a aspectos normativos da ESF.

Mais do que boa vontade talvez se trate do desconhecimento que os profissionais engajados no atendimento à população tenham a respeito do novo modelo assistencial. Como revelam Pinto e Santos (2010) em pesquisa feita junto a profissionais ligados à ESF, eles mesmos não têm muita clareza a respeito do SUS, das suas políticas e práticas. As autoras atribuem parte desse desconhecimento ao fato de que, dentre os profissionais que compõem as equipes de SF, os únicos que tiveram formação específica sobre a ESF são os ACS. Os demais profissionais que compõem as equipes não. 
Essa questão da boa vontade ou do desconhecimento dos ACS pode ser percebida também nos momentos em que elas dão às pacientes sugestões sobre como acelerar a obtenção de exames que já deviam ter sido feitos e não foram, ou sobre como acessar serviços específicos do posto.

O elo da política pública com a comunidade se corporifica na figura do Agente Comunitário de Saúde, que é a parte mais frágil do sistema e quem dispõe de menos recursos para resolver as demandas da população. São eles que "põem a cara para bater" e que muitas vezes tentam amenizar as deficiências que o sistema possui ${ }^{8}$. O sentimento de impotência dos ACS é frequiente. Enquanto elemento mais próximo do usuário, o ACS é que mais se percebe impotente para resolver as demandas.

\section{Considerações finais}

O artigo aponta que enquanto os operadores em saúde, notadamente as equipes de ESF, têm uma lista de atribuições que delimitam a sua atuação, as famílias não foram capacitadas para executar a sua parte da co-responsabilidade.

As famílias parecem apenas esperar pelos aspectos curativos e não estariam cientes das alterações que o novo modelo de atenção em saúde (com ênfase nos aspectos preventivos) representado pela ESF trouxe para eles.

Mesmo que pareça que a luta de forças desiguais (representada pelo conhecimento que se tem do sistema) penda para o lado dos ACS, estes têm um escopo de ação limitada. Se de um lado se joga a responsabilidade sobre as famílias, que têm que se adaptar as regras, de outro os ACS têm pouca ou nenhuma capacidade re-

8 Sobre a representação dos ACS como agentes de políticas públicas foi emblemática a situação em que uma determinada tarde ao percorrer o bairro com uma ACS esta passou a ser xingada por uma pessoa pela existência de esgoto ao ar livre e por valas malcheirosas. Ela mal tentou explicar que não era responsabilidade dela, mas da Prefeitura a o que a popular respondeu: “Sim, mas você não é funcionária da prefeitura?”. 
solutiva nas questões que demandem atenção secundária. E que, diga-se de passagem, não é da sua responsabilidade, mas pela qual são cobrados pela população.

Alonso (2003) chama a atenção para as expectativas despertadas na população, que nem sempre são cumpridas a despeito da boa vontade dos ACS. Na questão da co-responsabilidade teria que haver uma definição clara das responsabilidades de cada uma das partes. Enquanto que os ACS (assim como para os outros membros das equipes) têm uma lista de atribuições (verificar vacinas, realizar visitas domiciliares, entregar medicamentos, etc.) as famílias não foram capacitadas para assumir a sua parte da co-responsabilidade. Como propõem Santos e Andrade (2008), deveria ser oferecida educação sanitária ao paciente a fim de fomentar maior responsabilidade do cidadão com a própria saúde. Se não tiverem qualificação e conhecimento da nova concepção epistemológica dos serviços de saúde qual será a sua parte na co-responsabilidade? O que the cabe? Reclamar? Pressionar? Muito mais se o modelo biomédico induziu as famílias a abandonarem suas práticas em saúde e com isso as fez transferirem para os serviços médicos, e seus recursos tecnológicos e medicamentosos, a responsabilidade pelos cuidados. As famílias que ao longo de boa parte do século XX se tornaram dependentes desses cuidados medico-centrados - já que o modelo biomédico induziu as famílias a abandonarem suas práticas de saúde e com isso as fez transferirem para os serviços médicos, e seus recursos tecnológicos e medicamentosos, a responsabilidade pelos cuidados - agora são chamadas a reassumirem esses cuidados em outras bases. Elas são convocadas a serem co-responsáveis, mas não têm nem conhecimento sobre o que se espera delas nem têm condições de aceder a exames ou consultas especializadas que lhes possibilitem ter controle da sua dor. 


\section{Referências}

ALONSO, I. L. K. Luzes e sombras no ritual do encontro entre o universo profissional e o mundo da intimidade familiar : a intervenção profissional na saúde da família em âmbito domiciliar. Tese (Doutorado em Enfermagem) - Universidade Federal de Santa Catarina. Florianópolis 2003.

ANDRADE, L. O. M. de; BARRETO, C. I. de H.; BEZERRA, R. C.. Atenção Primária à saúde e Estratégia Saúde da Família. In: CAMPOS, G.W. de S. et al.. Tratado de Saúde Coletiva. São Paulo: Hucitec: Rio de Janeiro: Ed. Fiocruz, 2006. (Saúde em debate, 170).

BRASIL. Saúde da Família: uma estratégia para a reorientação do modelo assistencial. Brasília. Ministério da Saúde, Secretaria de Assistência à Saúde, 1997.

- Ministério da Saúde. Carta dos direitos dos usuários da saúde. Ministério da Saúde. - 2. ed. Brasília: Ministério da Saúde, 2007(a). (Série E. Legislação de Saúde)

Atenção Básica e a Saúde da Família. Disponível em: http://dab.saude.gov.br/atencaobasica.php\# diretriz. Acesso em 14 abr. 2010.

CORBO, A.D.; MOROSINI, M.V.G.C.; PONTES, A.L. de M.. Saúde da Família: construção de uma estratégia de atenção à saúde. In: MOROSINI, M.V.G.C; CORBO, A.D. orgs.). Modelos de atenção e a saúde da família. Rio de Janeiro: EPSJV/Fiocruz, 2007.

DECLARAÇÃO DE ALMA ATA. Conferência Internacional sobre Cuidados Primários de Saúde. Alma-Ata, URSS, 6-12 de setembro de 1978.

FAUSTO, Márcia Cristina Rodrigues; MATTA, Gustavo Corrêa. Atenção Primária à Saúde: histórico e perspectivas. In: MOROSINI, Márcia Valéria G.C.; CORBO, Anamaria D.Andrea (orgs.). Modelos de atenção e a saúde da família. Rio de Janeiro: EPSJV/Fiocruz, 2007.

FERREIRA, A. B. de H. Aurélio: dicionário da língua portuguesa. Curitiba: Ed. Positivo, 2008.

FRANCO Túlio Batista; MERHY Elias Emerson. Programa Saúde da Família: contradições de um Programa destinado à mudança do modelo tecnoassistencial para a saúde. Congresso da Associação Paulista de Saúde Pública. Águas de Lindóia, 1999. 
GELINSKI, C. R. O. G. Proteção social em saúde para famílias vulneráveis com monoparentalidade feminina via Estratégia Saúde da Família. Tese (Doutorado em Sociologia Política) Universidade Federal de Santa Catarina. Florianópolis, 2010. Disponível em: http://www.tede.ufsc.br/teses/PSOP0389-T.pdf

GRISOTTI, Márcia; PATRÍCIO, Zuleica Maria. A saúde coletiva entre discursos e práticas: a participação de uusários, trabalhadores e conselheiros de saúde no município de Florianópolis. Florianópolis: Ed. UFSC, 2006.

PINTO, D. G. C.; SANTOS, J. P. B. Profissionais da Atenção Básica: (Re)descobrindo o SUS. Trabalho de Conclusão de Curso (Especialização em Residência Integrada em Saúde da Família) - Universidade Federal de Santa Catarina. Florianópolis, 2010.

RIBEIRO, E.M. As várias abordagens da família no cenário do programa/estratégia de saúde da família (PSF). Revista LatinoAmericana de Enfermagem, v. 12, n.4, p.658-664. jul./ago. 2004.

SANTOS, L.; ANDRADE, L. O. M. de. Rede Interfederativa de Saúde. Revista Ciência \& Saúde Coletiva, artigo 0503/2008 Associação Brasileira de Pós-Graduação em Saúde. Disponível em: http://www. abrasco.org.br/cienciaesaudecoletiva/artigos/artigo_int.php?id_ artigo $=3022$. Acesso em 15 abr. 2010.

\begin{abstract}
The issue of co-responsibility provided by the Family Health Strategy

The new health care model, proposed in 1997 and implemented through the Family Health Strategy (ESF), focus on the health basic care and on the promotion of health and disease prevention. It is seen as a new way to deal with health care, in which the responsibilities for the cares should be shared by families and the ESF teams. This paper intends to analyze the meaning given to the term co-responsibility and the understandings that families - served by the ESF - have on the subject. The paper points out that while the health workers, notably the ESF teams, have a list of assignments that delimit their actions, the families do not know how to run their part on the co-responsibility process.
\end{abstract}

Keywords: co-responsibility, the Family Health Strategy, Primary Care. 